\title{
What is the Cost of Leptospirosis treatment in Jamaica? A Cross-sectional Study
}

\author{
Joneshia Bryan-Thomas", Kristen Collins, Jotham Omoregie, Annakay Levy \\ Department of Medical Technology, Northern Caribbean University, Manchester, Jamaica, West Indies \\ *Corresponding author: Joneshia.bryan-thomas@ncu.edu.jm
}

\begin{abstract}
Background: Periodic cases of leptospirosis are connected to contact with urine debased water, improper garbage disposal among several other factors. In many tropical regions such as Jamaica, leptospirosis is seen to increase during the rainy seasons and tapers down a little during the hotter climates. With the steady increase in outbreaks of this zoonosis, Leptospirosis has become a matter of grave concern. It has become a Public health volcano on the verge of eruption. Method: Six hundred participants were chosen from both a rural and an urban area in Jamaica. Interviews were carried out to ascertain the general awareness of the cost and cause of leptospirosis in Jamaica. Comparative analysis was done to gain needed information with regards to the cost of services and medication for this zoonotic illness. EBSCO host data base was searched for relevant literature that supported and enhanced the study. Simple analysis was achieved using the excel 2013 software. Results: Of the 600 participants $45 \%(n=270)$ were females and $55 \%(n=330)$ being males. For those living in the rustic division, the cost of treatment was found to be higher than those living in the urban area. The assessed cost to treat leptospirosis in the urban area is roughly $\$ 24,267 \mathrm{JMD}$ and if hospitalized it is approximated at $\$ 80,847 \mathrm{JMD}$. For those in the urban territory, if treated on time it would cost \$18,500 JMD. Conclusion: The cost of leptospirosis treatment in Jamaica is on the rise with this becoming a global public health threat. With the cost of proper treatment being higher than the regular under paid Jamaica (minimum wage \$6200 JMD).
\end{abstract}

\section{Keywords: Leptospirosis. Zoonosis, Outbreak, Financial cost}

Cite This Article: Joneshia Bryan-Thomas, Kristen Collins, Jotham Omoregie, and Annakay Levy, "What is the Cost of Leptospirosis treatment in Jamaica? A Cross-sectional Study." American Journal of Public Health Research, vol. 6, no. 3 (2018): 166-172. doi: 10.12691/ajphr-6-3-7.

\section{Introduction}

This research seeks to explore the nature of the cost of Leptospirosis treatment in Jamaica. Leptospirosis is a universally essential zoonotic illness caused by contamination with pathogenic leptospira bacterium. The disease normally causes damage to the kidney and liver which may be fatal in severe cases. [1,2] Leptospirosis is present worldwide and is especially important in developing countries, where sanitation is precarious. Sporadic cases are linked to contact with urine-contaminated water. In tropical countries, urban outbreaks can occur after floods in rainy season. [3] Mild non-lethal anicteric forms comprise most cases and can be easily confused with flu, dengue fever, other mild viral illnesses and P. vivax malaria. [3]

The quantitative exploration of the cost of leptospirosis treatment in Jamaica was assessed. Leptospirosis which was first noticed in Jamaica in 1953 is endemic to the country in question. [4] While rodents are the main carrier of the disease, the disease may be contracted from other infected animals. Leptospirosis typically follows heavy rainfalls or flooding. Climatic conditions and a lack of environmental sanitation are major causes of leptospirosis outbreaks. [5] The disease may be contracted from consumption of contaminated food, household water, playing in dirty water or garbage and while gardening in contaminated soil.

\subsection{Study Context and Conceptual Framework}

Red Hills, St. Andrew with a population of 159,231 is known as a rural area due to its density of residential features. Downtown Kingston an urban area with a population of 20,841 were randomly selected as the research sample. [6] Areas chosen in the same order were from St. Andrew which has an area of $455 \mathrm{~km}^{2}$ and a population of 573,369 also, Kingston which is $480 \mathrm{~km}^{2}$ and has a population of 937,700 . Data collected were limited to these areas; it was validated using Ministry of Health reports and journal reviews. The number of outbreaks which took place in both areas were noted and compared. The nature of the outbreaks leading to people being susceptible to the disease were observed and recorded.

\subsection{Problem Statement}

The miss identification and deleterious effects of leptospirosis is a case of grave concern. Leptospirosis is a public health concern coupled with treatment cost to low income communities. The number of leptospirosis outbreaks has been a major factor in the cost of treatment 
needed to be administered to infected patients. Cost of treatment fluctuates base on the number of outbreaks taking place.

\subsection{Rationale and Justification}

With the prevention of frequent outbreaks of leptospirosis, the sociological and economical cost that relates to this illness will be significantly reduced. Addressing the factors which support the disease spread will not only limit the amount of person who are susceptible to the disease but, reduction in unnecessary monetary supplies will be an asset.

\subsection{Purpose of the Study}

The purpose of this study is to highlight the main causes of leptospirosis in the areas of Red hills and Downtown Kingston in order to obtain the cost of leptospirosis treatment in the island of Jamaica.

\section{Literature Review}

\subsection{General Epidemiology and Clinical Presentation}

Leptospirosis is caused by a highly invasive spiral bacterium of the genus Leptospira. The infectious agent is capable of infecting both humans and animals. Leptospirosis has been reported to consist of roughly two phases of infection, acute and immune. These are branded by a wide yet inexhaustible range of symptoms that are considered nonspecific since they can also be found in other illnesses: fever, chills, headaches, conjunctival suffusion, excruciating myalgia, and arthralgia, and sometimes rigors vomiting, photophobia, a mucosal rash haemoptysis, hypotension, bradycardia, hepatosplenomegaly, and jaundice are also common. Death can occur from kidney failure, pulmonary haemorrhage, or other serious organ dysfunction $[7,8,9]$. Pathogenic Leptospira species do not replicate outside the host and are promptly inactivated in the earth when presented to extreme warmth, bright illumination, an assortment of disinfectants, and solidifying conditions. [10]

Be that as it may, when conditions are ideal, pathogenic leptospira can get by in water and wet soil for a considerable length of time to months. [11] Creatures that drink from, swim, or swim in natural water sources can end up tainted; presentation to untamed life or ranch creatures and their pee is additionally a hazard factor. Rats are an imperative repository and as such can be termed as a pathogenic server of Leptospira and the most widely recognized hotspot for human leptospirosis. [12]

The sickness is typically transmitted by means of immediate or roundabout contact between mucous films or potentially bargained skin and urine, emissions, or sullied water from tainted creatures. Leptospira does not survive well in corrosive urine but rather stay practical in soluble urine. Therefore, herbivores and creatures whose eating routine produces soluble urine are moderately more vital as shedders than are makers of corrosive urine.

Leptospirosis may show up in either a mellow or serious frame, and the two kinds have comparable hatching periods 7- 14 days. Most leptospiral diseases are mellow and basically all pathogenic serotypes cause febrile ailment in people. The most unmistakable indication is perpetual fluctuating fever with temperatures of $38.9-41.9^{\circ} \mathrm{C}$ for 2-12 days or increasingly, serious cerebral pain, muscle agony, and queasiness that holds on for roughly 7 days. Jaundice happens amid this stage in more extreme diseases. [13]

In the proper diagnosis of leptospirosis that is seen to increase in Jamaica during the storm seasons, the illness poses a challenge as symptoms of this treatable zoonotic illness mimics other seasonal illnesses such as dengue and influenza along with a host of others. Upon suspecting that a patient may be infected a complete blood count (CBC), along with general kidney function tests coupled with confirmatory tests for leptospirosis would be ordered to ascertain the general picture of health of the patient. Significant differences in haemoglobin concentrations, haematocrits, counts of erythrocytes, leucocytes, neutrophils, platelets, and concentrations of creatinine, urea, protein, and albumin when comparing those with mild to those with severe disease is usually observed. Transmission of leptospirosis was first recognized as an occupational hazard in industries related to agriculture, sewer maintenance, and animal husbandry, and results from direct or indirect contact with the urine of infected animals [14]. A wide range of laboratory direct tests are available for the testing of this zoonotic illness such as, direct observation of leptospires using darkfield microscopy, enzyme linked immunosorbent assay and microscopic agglutination test, real time polymerase chain reaction. These have been listed from the least specific to the most specify along with from the least expensive to the most expensive. The least also is from the most available in Jamaica to the least available [15].

The drugs that would require the extinction of leptospirosis from the body would be penicillin, amoxicillin or erythromycin. Some patients may require IV antibiotics and supportive hospital care such as rehydration. [16]

Due to overlapping clinical features with other febrile illnesses, the diagnosis of leptospirosis is often overlooked, resulting in delay in treatment and increased mortality [17]. In a study conducted by [18] which tested the prevalence of leptospirosis, 590 patients with dengue-like illnesses were tested using the Leptospira IgM dipstick and dengue enzyme-linked immunosorbent assays. Leptospira IgM antibodies were found in 27 (5.0\%) patients. Dengue IgM negative $(6.9 \%$ versus $2.5 \%, \mathrm{P}<0.05)$ and dengue IgG positive patients $(8.0 \%$ versus $3.5 \%, \mathrm{P}<0.01)$ were more likely to be leptospira IgM positive. Fever, skin rash, central nervous system and respiratory involvement were the most common presenting features. The presence of arthralgia $(P=0.016)$, hepatitis $(P=0.000)$, jaundice $(P=0.003)$, splenomegaly $(\mathrm{P}=0.041)$ and haematuria $(\mathrm{P}=0.029)$ were associated with leptospirosis. In countries with an endemicity of leptospirosis and dengue it is important that patients with dengue-like illnesses, especially those with no serological evidence of current primary dengue infection, be investigated for leptospirosis. [18]

\section{Methodology}

A convenient sample of six hundred (600) participants were invited to participate in the study. Three hundred 
from each region of analysis. The information obtained for the compilation of this research was done in the form of surveys that captured general education and affordability index from both the rural and urban areas along with additional sources such as interviews, information from case studies and also census reports from Jamaica Information Service (JIS) literature reviews using the EBSCO host data base was utilized. The local printed media were also helpful tools in the gathering of local information regarding leptospirosis. Data obtained were limited to the rural area (Red Hills) and the urban area (Downtown Kingston). After much observation, it was noted that the cost of treatment for leptospirosis fluctuates base on the number of outbreaks and the availability of the equipment used for treatment. To obtain the cost of treatment for leptospirosis; the pharmacies in both regions were visited and questioned, along with the general practitioners, hospitals, general and private labs and averages were calculated.

\section{Results}

In the areas of Downtown Kingston and Red Hills; a total of three hundred questionnaires, (one hundred per mile) were spanned out to the population to fulfil the known or speculative knowledge of Leptospirosis and its associative features. Of the population in Downtown Kingston, 60\% were males $(n=180)$ with the remaining $40 \%$ being females $(n=120)$ (see Figure 8$)$. While in the rural area of Red Hills, there was a sharing equivalence of $50 \%$ for both male $(n=150)$ and female $(n=150)$ with mean age being 33 years old and 36 years old, ranging from (26 years to 30 years) and (31 and over) for both Downtown Kingston and Red Hills respectively. The noticed trend in Downtown, 49\% $(n=59)$ of the females disposed of their garbage by the implemented Sanitary Engineers while $51 \%(n=40)$ of males burned wastes in their backyard. On the other hand, it is the entirely drastic and opposite difference in Red Hills; 93\% ( $\mathrm{n}=$ of their population disposed of their garbage in sanitation bins which are collected weekly and the remaining $7 \%$ burned their garbage (see Figure 1). These numbers can be liaised to the high awareness and contraction of Leptospira bacteria in Downtown, with the accumulative $89 \%$ of both males and females knowing what it is; while $8 \%$ of the females and $17 \%$ of the males contracting the virus too. Luckily, the knowledge of the disease in Red Hills was vast, this is due to the full $100 \%$ of the populace being aware of it (see Figure 2). The fallen victims had symptoms of hyperpyrexia (fever of high temperatures), myalgia and headaches. There was a great disparity between the cost of treatment for both the rural and urban area. It was noticed that, the cost of treatment at medical facilities near the vicinity of red hills were far more expensive than that of Downtown, Kingston; ranging from $>\$ 15,000$ and $\$ 5,000-\$ 10,000$ respectively. There was a whopping $97 \%$ of the people of Downtown (see Figure 3), Kingston both male and female living on plain lands and a 3\% living near swamps. Red Hills is known for its mountain-like terrains; therefore, $99 \%$ of the populace resides on the hillside and is supplied with water from their taps (see Figure 6). The city of Downtown, Kingston is also supplied with water through taps by the governmental facility called National Water Commission where $77 \%$ of the collective respondents are users of this service. On the other hand, the remaining $23 \%$ make use of the water storage system, tanks. Continuing with Downtown, from the $60 \%$ of male respondents, a staggering $5 \%$ of them washed fruits before consumption. While from the 40-percentage females, $28 \%$ washed their fruits before consumption. In the process of storing excess food, the most common accumulative preservative method was leaving the remaining food in the pots on the stove with a value of $87 \%$, followed by $13 \%$ for storing food in the refrigerator. On the contrary, the most popular storage method collected from the data for the people of Red Hills was in the refrigerator in containers with an $86 \%$ value. The remaining $14 \%$ was divided equally between leaving pots on the stove with food and on the kitchen counter. Additionally, it was noticed that the trend for having livestock on one's property was a commonality for the female versus the males; who both had values of $63 \%$ and $37 \%$ respectively. Separate and apart from that, the most frequent animal/(s) the people of Red Hills come into contact with are the domesticated animals such as dogs and cats.

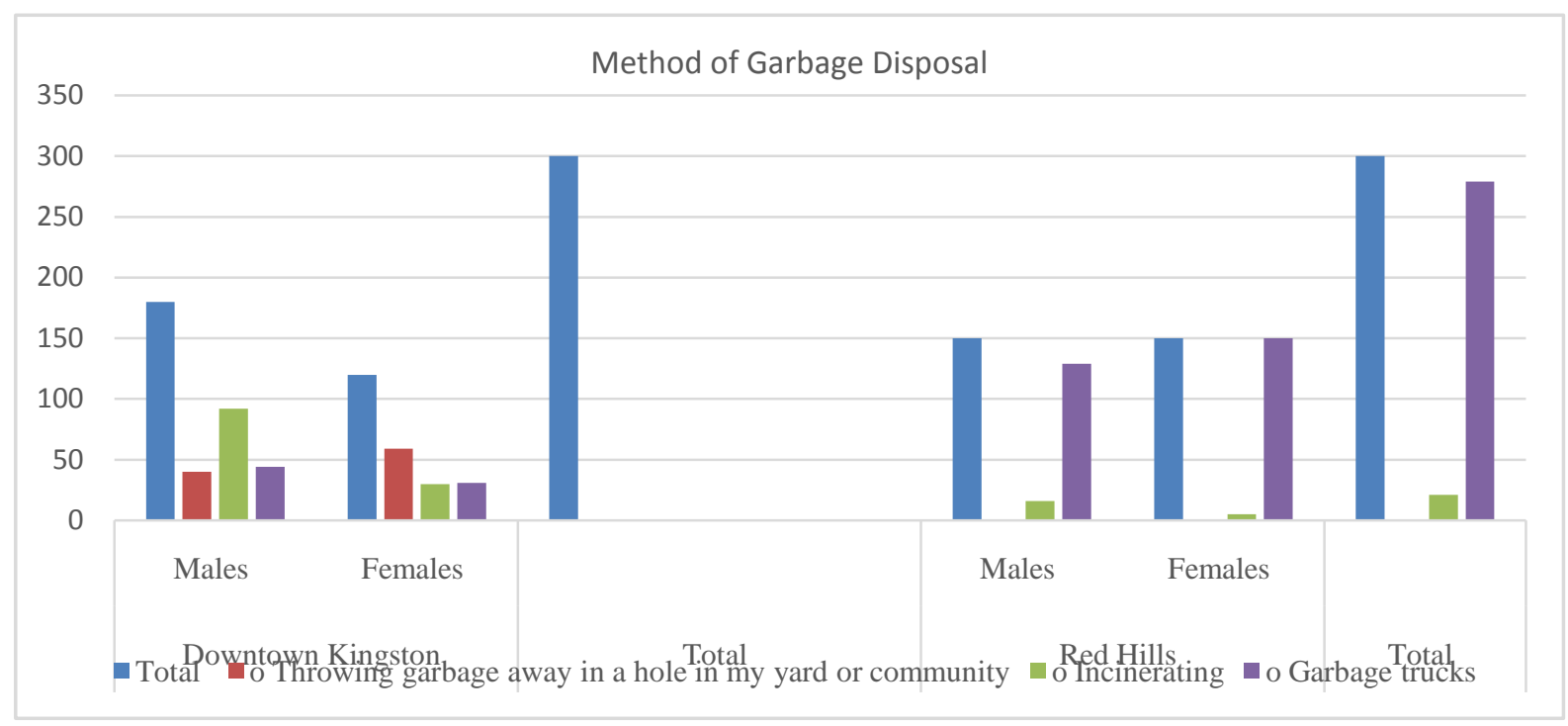

Figure 1. Methods of garbage disposal 


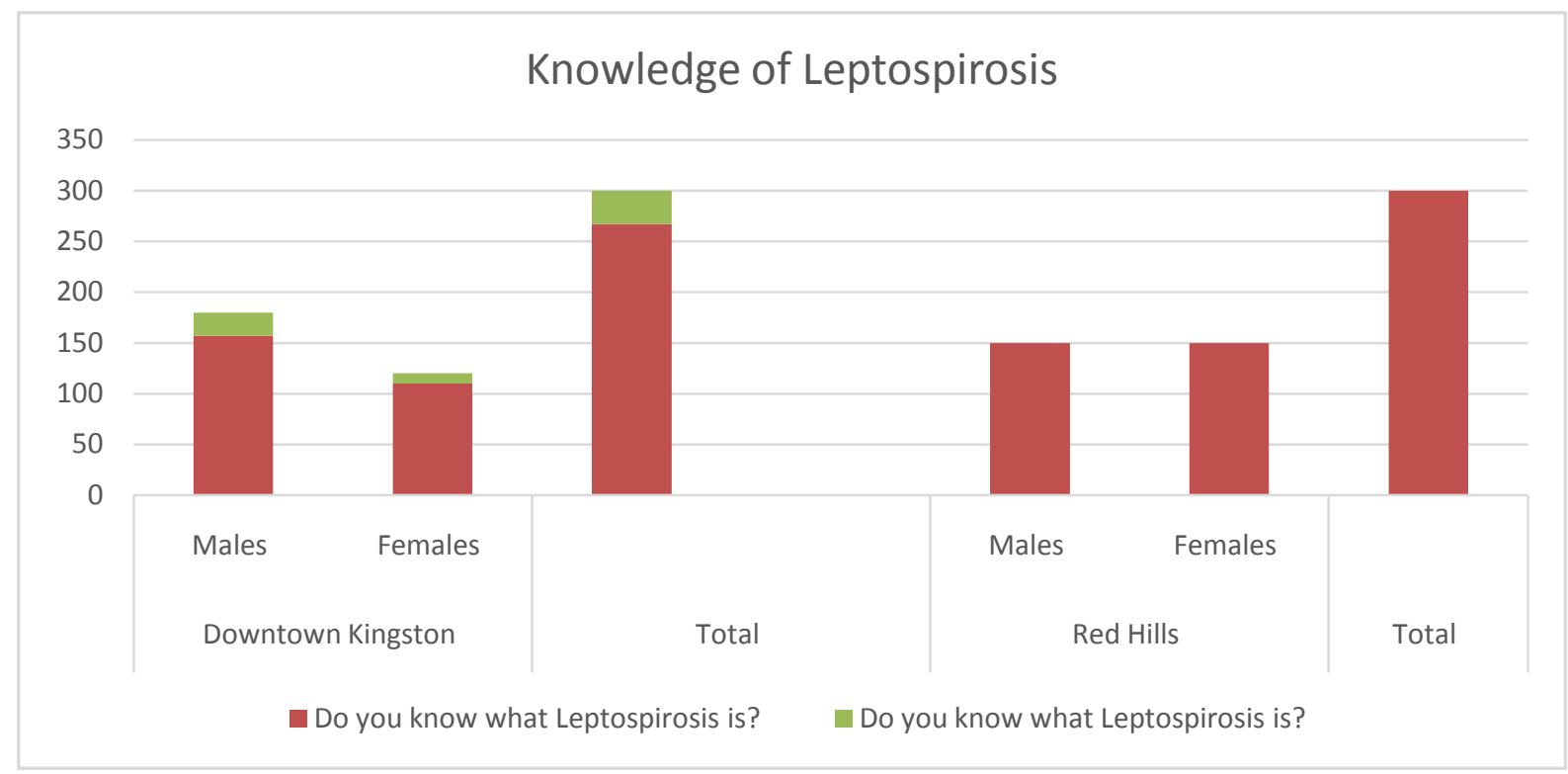

Figure 2. Knowledge of Leptospirosis

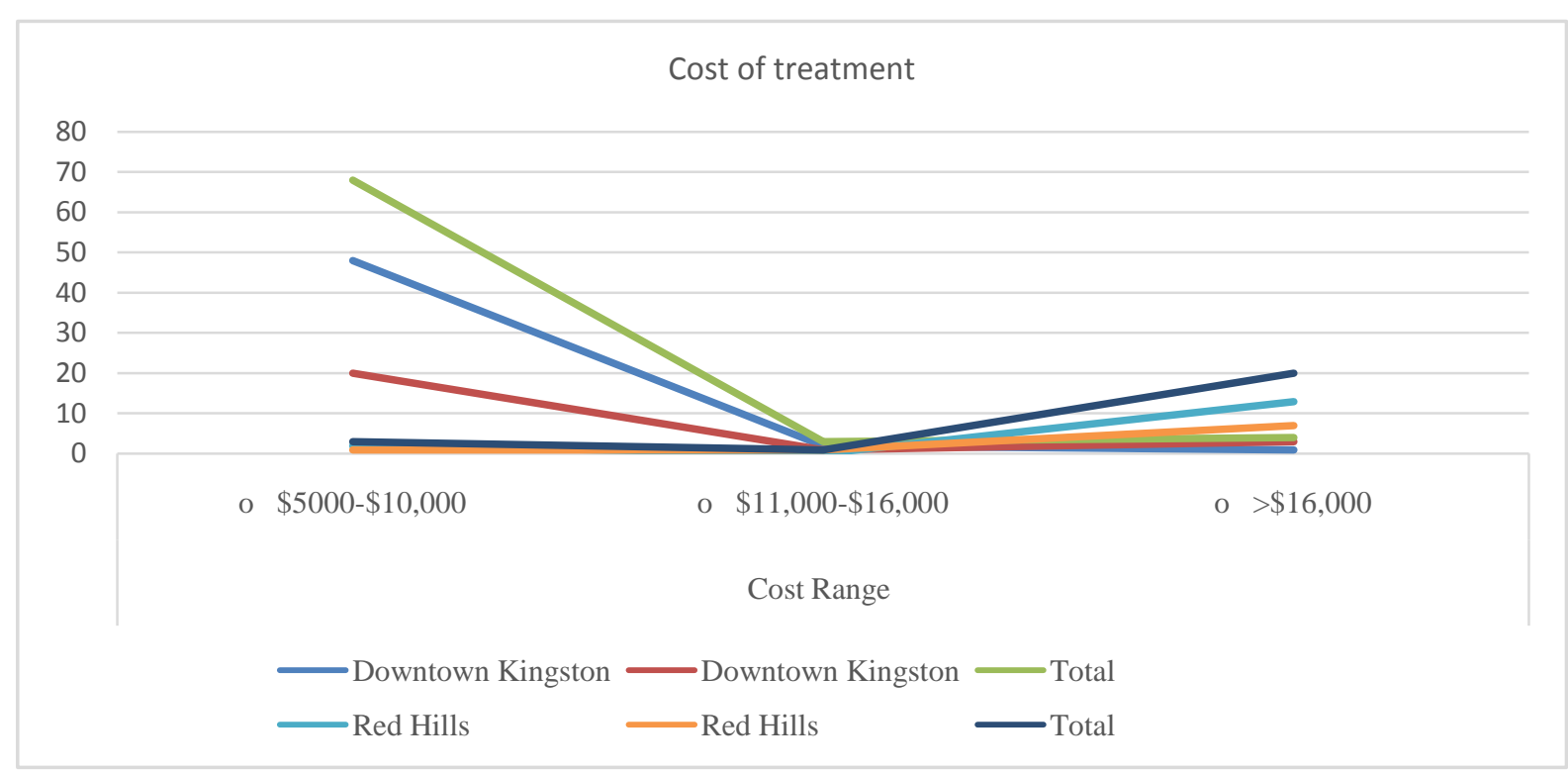

Figure 3. Cost of treatment

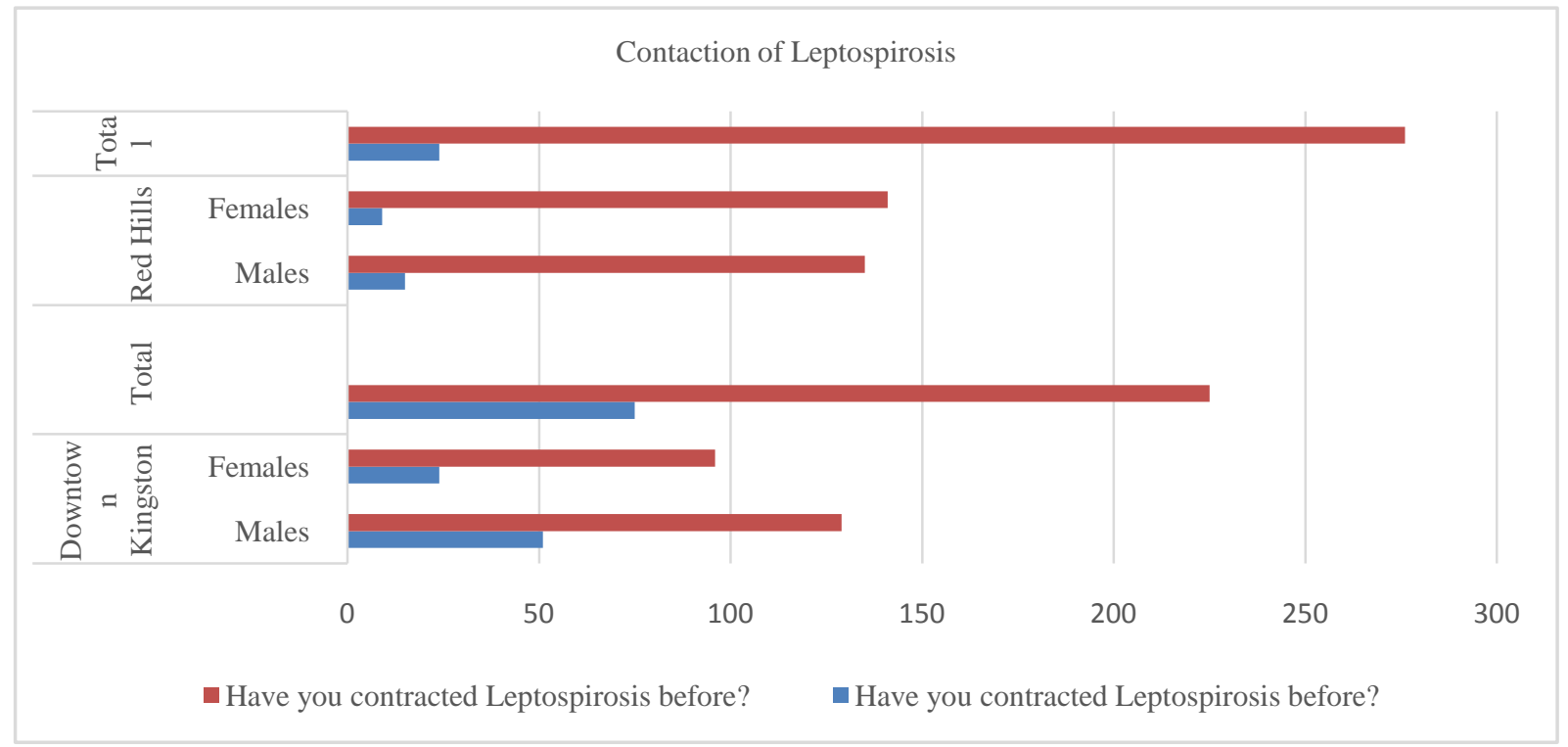

Figure 4. Contraction of Leptospirosis 


\section{Symptons}

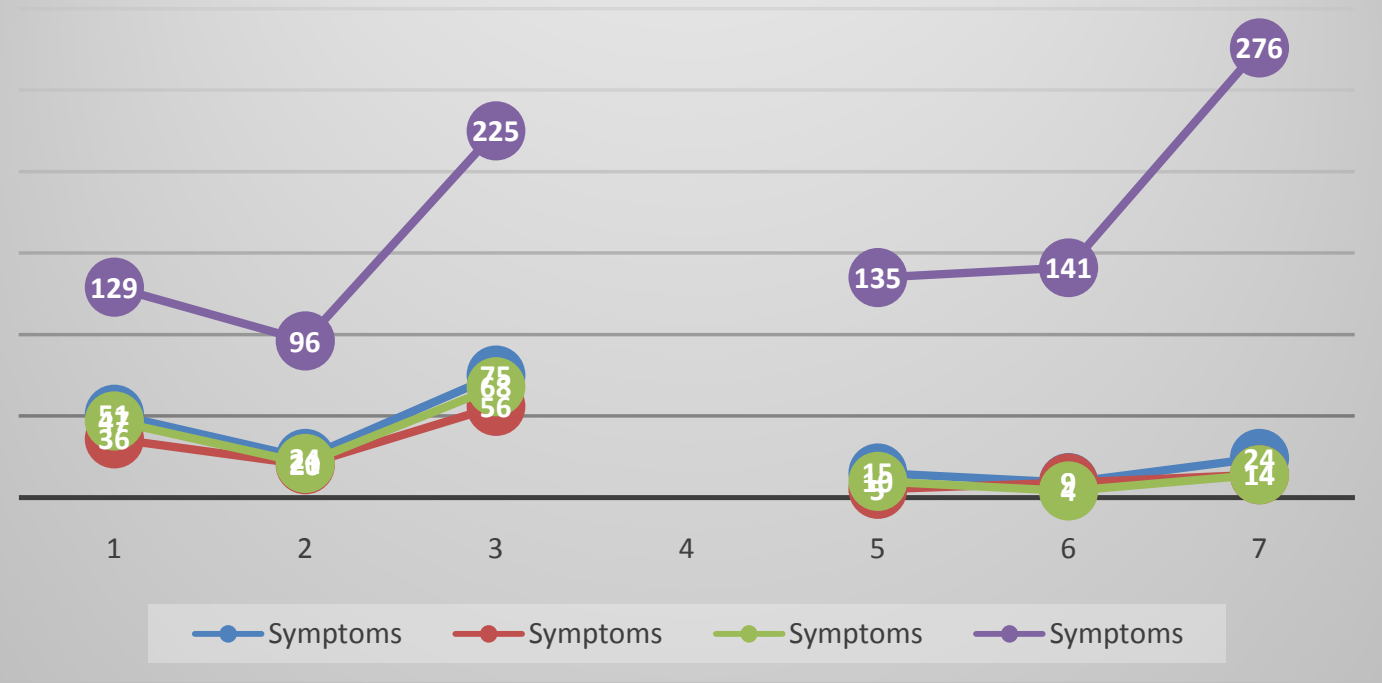

Figure 5. Symptoms experienced by participants who had Leptospirosis

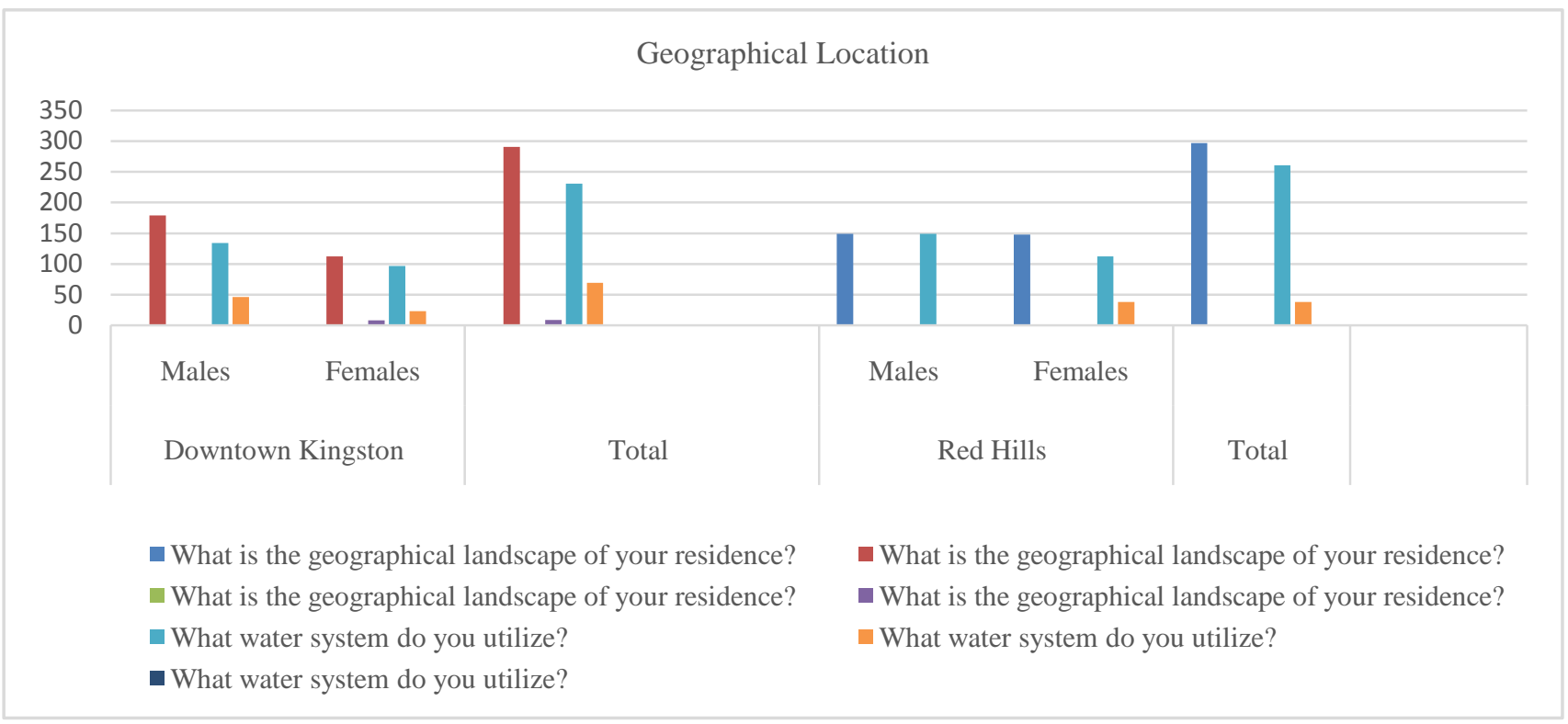

Figure 6. Geographical Location

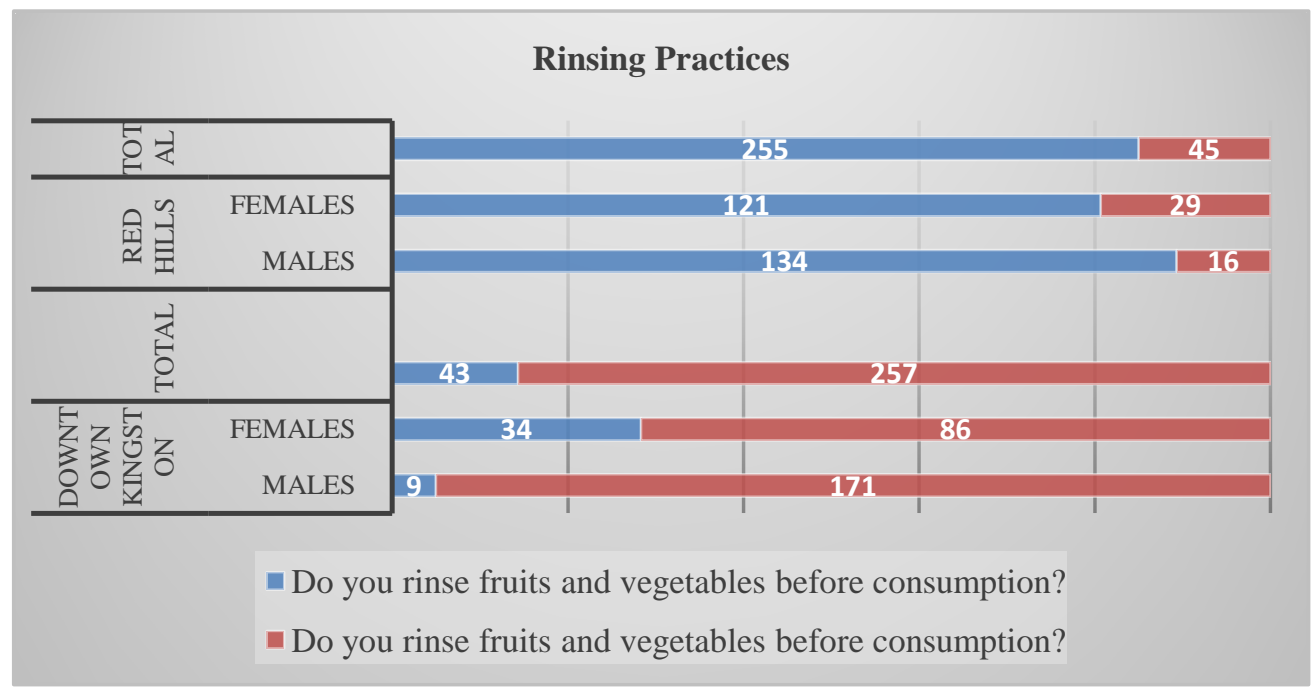

Figure 7. Rinsing fruits and vegetables before consumption 


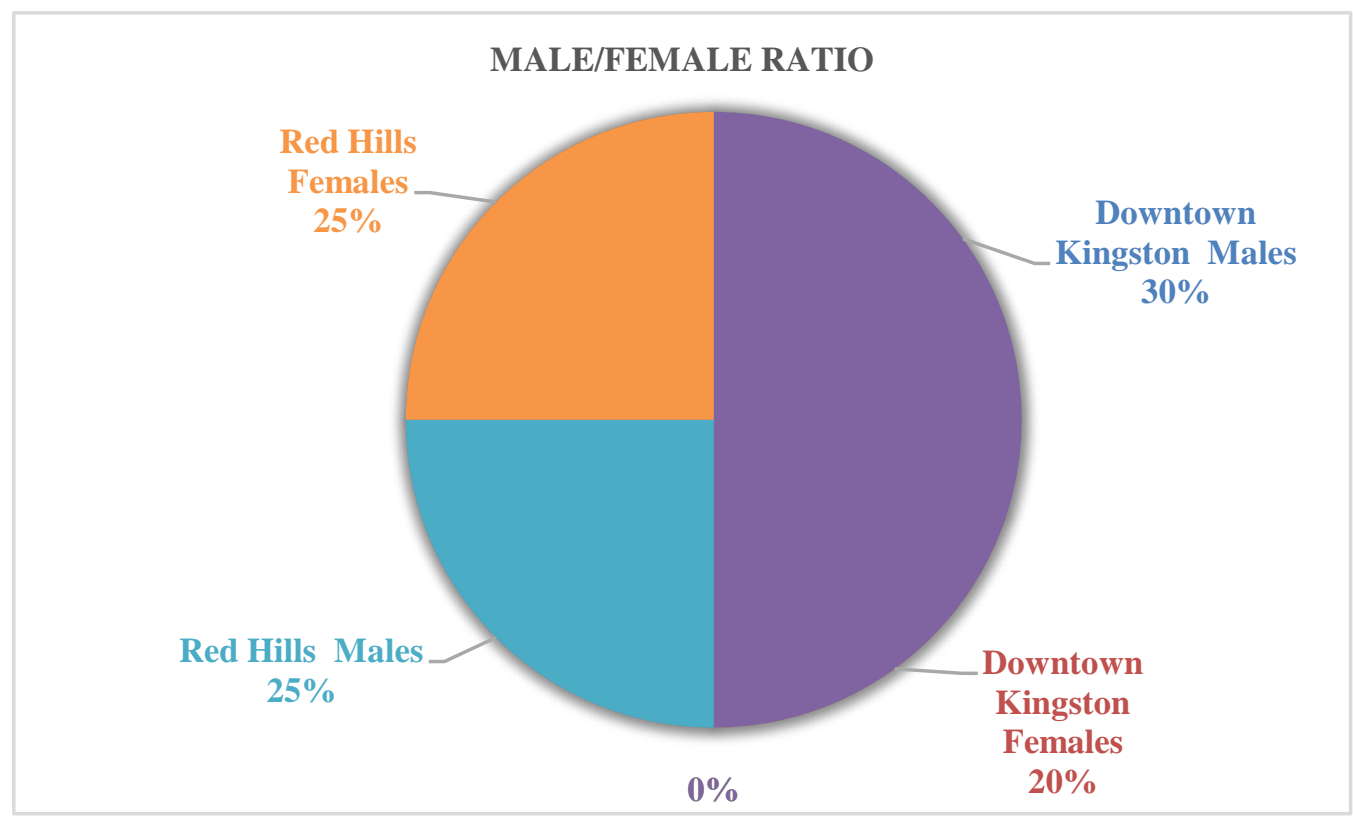

Figure 8. Male/ female ratio

\section{Discussion}

The cost of treatment based on research done is more costly in the rural area but if delaying in treatment in the urban area, it will become costlier because the disease leptospirosis can evolve into other more severe illnesses such as meningitis. Typically, in the urban area, one visiting a General Practitioner, the cost is on average approximately $\$ 4,000$ to $5,000 \mathrm{JMD}$. The next stage would be to visit a laboratory for the leptospira test which approx. averages to be $\$ 4,500$ to 6,000 JMD. While awaiting a day or two for the results a prescription for the signs and symptoms would be filled out to average at about $\$ 6,000$ to $\$ 7,500 \mathrm{JMD}$ for drugs such as cataflam, Zyrtec, and Cefuroxime just to name a few. Once test is positive for leptospira the doctor will prescribe doxycycline which is average approx. \$3,500JMD based on the average dosage needed.

Generally, the individuals in the urban area see symptoms as indication of a cold or flow and use natural methods to treat this until it worsens into meningitis for example where the cost of treatment is three times the amount for leptospirosis. For those living in the rural division, the cost of treatment is higher than the urban is provided that they are treated soon after symptoms arise. The cost to see a General Practitioner is approx. \$5,500 to $6,000 \mathrm{JMD}$. The next stage being the laboratory which cost approx. $\$ 5,500$ to $\$ 7,000$ for the test. If positive and severe the persons in the rural area prefers a private facility, which cost approx. \$56,580 JMD for an overnight stay with intravenous medications. With a prescription to fill for doxycycline which averages to cost \$4,380 JMD. Additionally, the cost for medication to treat symptoms are approx. $\$ 8,887$ to $\$ 9,750 \mathrm{JMD}$. The estimated total cost to treat leptospirosis in the urban region is approx. $\$ 24,267$ JMD and if hospitalized it is approximated at $\$ 80,847$ JMD. For those in the urban area, if treated on time it would cost $\$ 18,500$ JMD.

Leptospirosis affects both humans and animals in rural and urban areas. Overall, Leptospirosis outbreaks were most prevalent in the urban area of Downtown, Kingston due to its highly improper garbage disposal system, where $49 \%$ of the females disposed of their garbage in the communal drums. However, this is where the issue arises; although the garbage is disposed of properly, there were on the field complaints about delayed visitations from the Sanitary Engineers. National Solid Waste Management Authority (NSWMA) was contacted for a voicing for the validation of what the members of Downtown, Kingston had to say. According to the governmental facility, their mission is to keep Jamaica clean, with the motto of "Jamaica's beauty is our duty". The most popular complaint "the government doesn't care about ghetto people" became an ear-bug at the end of the survey process. The infection appeared to be more rampant during the rainy seasons where the drains become clogged. This is so because the environmental conditions are more favourable to the sustenance of the bacteria. As a result of this, there is over saturation of water in the soils, thus resulting in surface runoff. This surface runoff transports the contaminated soil that is laddened with the Leptospira that is typically excreted through the host's urine; where it ends up in a variety of places: such as, common ground (your backyard) which is a flat land where the water settles. Leptospirosis is a zoonotic disease, the crossreactivity of the bacteria to humans is very much possible if contact with mucous membranes of humans occurs. Especially when precautionary measures for some is nonexistent. The high incidence of the female sample that had livestock on their property were more prone to the opportunity of getting the disease.

Research from interviews showed that the peak season in "Downtown Kingston" for leptospirosis is in the rainy season which corresponds to information found in several journals. Due to the sewage and drainage systems being frequently clogged, and garbage left on the floors would be washed away into a huddle because of the rain. Workers in downtown confessed on several occasions to the drinking of dirty water, getting splashed by it with a vehicle and even walking through it because some sections would become flooded. Workers moved on to say that garbage in this area is never collected on time and 
they can see rats around this garbage areas and even running across the roads. At times it can get severe where a rodent would run across their legs in hunt for its next meal.

Typically, the symptoms of Leptospirosis can be similar to that of other ailments such as malaria and influenza. Symptoms such as high fever, myalgia, headaches and chills. Therefore, the initial assumption, one has become a fallen victim of the 'flu'. In the field, there were voiced complaints about not having monetary funds to visit private doctors and the public health sector is 'a whole day process, which the sick tries to avoid. So, what they do is try to remedy the illness with naturopathic medicine. Typically, this may help for a while and the individual may think they are fine; until the re-emergence of the primary symptoms. The infection has now moved into its second stage where it can become deadly due to a renal infection or meningitis.

To derive the suspected ailment the attending physician may order blood and urine test to aid in diagnosis. For confirmation, antibodies are looked for in the blood to the specific microbe.

\section{Conclusion}

The cost of leptospirosis treatment in Jamaica can be controlled based on how we live, by preventative methods such as proper garage disposal, and wearing the proper protective equipment. From the results obtained, it can therefore be concluded that the cost of leptospirosis treatment is highly motivated by the amount of outbreaks that takes place.

\section{Recommendations}

1. The National Solid Waste Agency (NSWA) can visit the urban areas more frequently for garbage collection, which would greatly reduce the amounts of outbreaks and hence reduces the cost that citizens would spend on treatment.

2. Once showing symptoms of the disease, residence must be educated to seek medical care before the situation progresses as, if left untreated or delayed treatment in leptospirosis can evolve into meningitis which is thrice the cost of leptospirosis.

3. Practice proper sanitation methods when eating and using the restroom to avoid contracting the disease to in the end save time and cost.

4. Educating the minds of those who are unaware of what Leptospirosis, the symptoms and treatment attached.

\section{Acknowledgments}

We are grateful to those persons who were willing to sign the consent from to be involved in the investigation.
To those who gave words of support while the project was being done we say thank you.

\section{References}

[1] Vijayachari P, Sugunan AP, Shriram An. Leptospirosis: an emerging global public health problem. Journal of Biosciences. 2008; 33(4): 557-569.

[2] Memantine | Side Effects, Dosage, Uses, and More. Healthline. [accessed $2018 \mathrm{Mar}$ ] https://www.healthline.com/health/memantine-oral-tablet.

[3] D. Diament. Leptospirosis. 2016 [accessed 2018 Mar 12]; 45(1): 40-41.

[4] Schneider MC, Michel Jancloes, Daniel F. Buss, Sylvain Aldighieri, Eric Bertherat, Patricia Najera, Deise I. Galan, Kara Durski, Marcos A. Espinal. Leptospirosis: A Silent Epidemic Disease. 2013 Dec [accessed 2013 Dec 23]. https://www.ncbi.nlm.nih.gov/pmc/articles/PMC3881163/.

[5] Paul Allwooda, Claudia Muñoz-Zanzib, Martin Changa, Paul D. Brown. Journal of Infection and Public Health. Knowledge, perceptions, and environmental risk factors among Jamaican households with a history of leptospirosis.

[6] Kingston. Jamaica Information Service. [accessed 2018 Mar 12]. http://jis.gov.jm/information/parish-profiles/parish-profilekingston/.

[7] Fentahun T, Alemayehu M. Leptospirosis and its public health significance: a review. Eur J Appl Sci. 2012; 4(6): 238-44.

[8] Kasper LD, Braunwald E, Fauci SA, Hauser LS, Longo LD, Jameson LJ. Harrison's principles of internal medicine, 16th edn. New York: Mcgraw-Hill; 2005. pp. 988-91.

[9] Craig E, Greene JE, Sykes AB. Infectious diseases of the dog and cat, 3rd edn. Canada: Saunders; 2006. pp. 402-17.

[10] Evangelista KV, Coburn J. Future microbiology. 2010 Sep [accessed 2018 Mar 12]. https://www.ncbi.nlm.nih.gov/pmc/articles/PMC3037011/Science Direct. Leptospirosis. 2008. Handbook of Small Animal Practice (Fifth Edition).

[11] Wynwood SJ, Graham GC, Weier SL, Collet TA, McKay DB, Craig SB. Leptospirosis from water sources. Pathogens and Global Health. 2014 Oct [accessed 2018 Mar 12]. https://www.ncbi.nlm.nih.gov/pmc/articles/PMC4241785/.

[12] State of Hawaii. Lepto Bro re4 - Hawaii Department of Health. 2008 [accessed 2018 Mar 12].

http://www.bing.com/cr?IG=B378C4069920435BA5FBF0301688 F780\&CID=3928DF25AD0C60D80A13D495ACA361E8\&rd=1 \&h=DPRPYBk3FIRhsGpoN96yaeOqqunJiR934m1fWZJjao\&v=1\&r=http\%3a\%2f\%2fhealth.h awaii.gov\%2fabout\%2ffiles\%2f2013\%2f06\%2fleptobrochure.pdf \&p=DevEx,5067.1.

[13] R. Cichon, J. Uradziński. ZOONOSES. Leptospirosis - an overview | ScienceDirect Topics. 2003 [accessed 2018 Mar 12]. https://www.sciencedirect.com/topics/agricultural-and-biologicalsciences/leptospirosis.

[14] Wynwood, S. J., Graham, G. C., Weier, S. L., Collet, T. A., McKay, D. B., \& Craig, S. B. (2014). Leptospirosis from water sources. Pathogens and Global Health, 108(7), 334-338.

[15] Musso, D., Scola, B.,(2013). Laboratory diagnosis of Leptospirosis: A challenge. Journal of Microbiology, Immunology and Infection. Volume 46, Issue 4, p. 245-252.

[16] Davis CP. Leptospirosis Symptoms, Diagnosis, Treatment \& Vaccine. MedicineNet. 2017 Oct 17 [accessed 2018 Mar 12]. https://www.medicinenet.com/leptospirosis/article.htm.

[17] Brown MG, Vickers IE, Salas RA, Smikle MF. Leptospirosis in suspected cases of dengue in Jamaica, 2002-2007. Tropical doctor. 2010 Apr [accessed 2018 Apr 17]. https://www.ncbi.nlm.nih.gov/pubmed/20305103.

[18] Michelle G Brown, Ivan E Vickers, Rose Alba Salas. Leptospirosis in suspected cases of dengue in Jamaica, 2002-2007. Tropical Doctor. 2010 Mar 19. 